\title{
Determination of Itraconazole and Hydroxyitraconazole in Plasma by Use of Liquid Chromatography-Tandem Mass Spectrometry with On-line Solid-Phase Extraction
}

\author{
Michael Vogeser ${ }^{*}$, Ute Spöhrer ${ }^{2}$ and Xaver Schiel ${ }^{3}$ \\ 1 Institute of Clinical Chemistry, \\ 2 Hospital Pharmacy, \\ 3 Department of Internal Medicine III, \\ Hospital of the University of Munich, Munich, Germany
}

In this paper a method for the simultaneous quantification of the anti-fungal drug itraconazole and its co-active metabolite hydroxyitraconazole in plasma employing liquid chromatography tandem-mass spectrometry and automated solid-phase extraction is described. The method proved rugged, enables short turn-around times and is highly specific. Since there is growing evidence for the importance of therapeutic drug monitoring of itraconazole in the prophylaxis and treatment of invasive fungal infections, the method described here is of interest for a large number of tertiary care hospital laboratories. Clin Chem Lab Med 2003; 41(7):915-920

Key words: Itraconazole; Hydroxyitraconazole; Liquid chromatography-tandem mass spectrometry.

Abbreviations: CYP, cytochrome-P450; LC-MS; liquid chromatography-mass spectrometry; LC-TMS, liquid chromatography-tandem mass spectrometry; MRM, multiple reaction monitoring; $\mathrm{m} / \mathrm{z}$, for mass-to-charge ratio.

\section{Introduction}

Invasive fungal infections have increased in incidence over the past years and now are among the most frequent causes of morbidity and mortality in immunocompromised patients, particularly in patients with neutropenia $(1,2)$. Amphotericin B desoxycholate is currently the standard empirical anti-fungal therapy in neutropenic patients with malignancies, who have persistent fever that does not respond to broad-spectrum antibacterial treatment (3). This therapy, however, is accompanied by severe side effects. Itraconazole is a new less toxic alternative for amphotericin B. Efficiency could be demonstrated for prophylaxis of fungal infections $(4,5)$, for empirical anti-fungal therapy $(6)$, as well as for the treatment of proven invasive aspergillosis (7).

Itraconazole is a triazole compound, with activity against Aspergillus fumigatus and Candida species as

\footnotetext{
*E-mail of the corresponding author:

Michael.Vogeser@klch.med.uni-muenchen.de
}

the most relevant fungal pathogens in neutropenic patients; it is meanwhile available as an intravenous and an oral formulation. Often itraconazole therapy is started with intravenous application and is subsequently switched to oral application for longer time periods $(8,9)$. The drug is highly lipophilic and only ionized at low $\mathrm{pH}\left(\mathrm{pK}_{\mathrm{a}}=3.7(10)\right)$. The absolute availability of capsules in healthy volunteers under fasting conditions is about 55\%; it is increased after a meal and markedly reduced by antacida. In immuno-compromised patients the absorption of itraconazole is often affected by gastrointestinal disorders caused by cytotoxic chemotherapy or graft-versus-host disease. Itraconazole is $99.8 \%$ bound to human plasma proteins and its apparent volume of distribution is about $11 \mathrm{l} / \mathrm{kg}$. The drug is extensively metabolized by hepatic cytochrome-P450 (CYP) enzymes (10, 11). Among the metabolites hydroxyitraconazole is of particular interest because it exerts anti-fungal activity similar to that of itraconazole (12) and typical plasma concentrations are usually slightly higher compared to that of itraconazole. Co-administration of itraconazole with drugs that inhibit CYP3A4 can lead to increased serum concentrations (e.g., macrolide antibiotics such as erythromycin, HIV protease inhibitors such as indinavir), whereas inductors of CYP3A4 can decrease serum concentrations of itraconazole (e.g., phenytoin, carbamazepine, isoniazid, rifabutin, inhibitors of reverse transcriptase such as nevirapine, immunosuppressants such as cyclosporine). After a single oral dose, the terminal elimination half-life of itraconazole is about 24 hours. The drug exhibits a dose-dependent saturable pharmacokinetic behavior. Renal failure hardly affects the pharmacokinetic properties of itraconazole but little is known about the effects of hepatic failure. Itraconazole is in general well tolerated; gastrointestinal disturbances and dizziness are the most frequently reported adverse effects. However, in animals negative inotropic effects have been shown, and there is concern about cases of severe liver toxicity possibly associated with itraconazole treatment (13).

Given a marked intra- and inter-patient variability in the pharmacokinetics of itraconazole, dose individualization of itraconazole according to trough plasma levels has meanwhile been shown to be useful. Target trough plasma concentrations of at least $500 \mathrm{ng} / \mathrm{ml}$ are recommended for prophylaxis of invasive fungal infections (14-17), whereas higher trough levels are probably beneficial in cases of infection.

It is evident from this background that the availability of reliable analytical methods for the quantification of itraconazole in plasma is of growing importance for 
laboratories in tertiary care hospitals. Numerous HPLC methods for this purpose employing different techniques of sample preparation and detection have been published and are in clinical use (18-31). High analytical specificity is of particular importance for therapeutic drug monitoring of itraconazole since patients receiving itraconazole for prophylaxis or treatment of fungal infections are usually treated with several other drugs and these drugs or their respective metabolites may potentially interfere with itraconazole quantification. More importantly, simultaneous quantification of itraconazole and hydroxyitraconazole in plasma using non-specific techniques of HPLC detection and isocratic elution is in our experience problematic due to co-eluting "endogenous" peaks in individual blank samples. Because liquid chromatography-tandem mass spectrometry (LC-TMS) at present offers the highest attainable analytical specificity for drug monitoring we decided to develop a LC-TMS method for the determination of itraconazole and hydroxyitraconazole in plasma with automated sample preparation allowing short turn-around times in the clinical laboratory.

\section{Materials and Methods}

\section{Analytical procedure}

\section{Chemicals}

Itraconazole, hydroxyitraconazole and the compound R51012 (a dimethyl homolog of itraconazole) used as the internal standard were obtained from ORTHO BIOTECH (Neuss, Germany) (Figure $1 \mathrm{~A}$ and $\mathrm{B}$ ); stock solutions of these compounds were made in methanol (approx. $50 \mathrm{mg} / \mathrm{l}$ ). Ammonium acetate was from Merck (Darmstadt, Germany); a 200 mM stock solution was made in water. Methanol and water were of HPLC grade (Baker, Deventer, The Netherlands).

\section{Instruments}

A Waters Alliance 2690 HPLC module (Waters, Milford, USA) was used, coupled to a Micromass Quattro LC-tandem mass

A

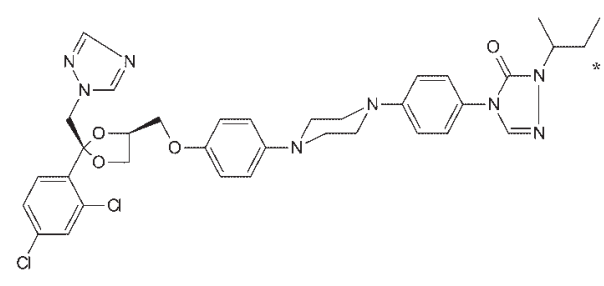

B

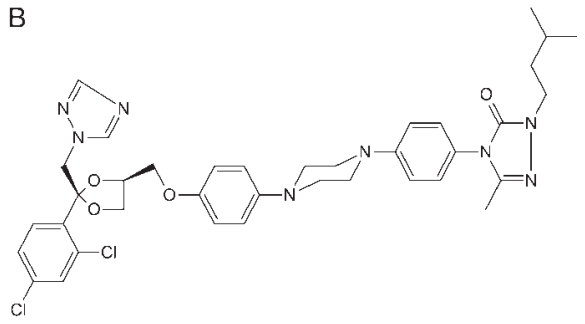

Figure 1 A: Chemical structure of itraconazole; * denotes the site of hydroxylation of hydroxyitraconazole. B: Chemical structure of the itraconazole homolog R51012 used as the internal standard. spectrometry system (Micromass, Manchester, UK) with a split of approximately 1:10.

\section{Standards}

A stock calibrator was prepared by spiking a plasma pool from patients not treated with itraconazole with the stock solutions of itraconazole and hydroxyitraconazole, respectively, to obtain concentrations of $4000 \mu \mathrm{g} / \mathrm{l}$ for both analytes. After careful mixing and overnight equilibration, working calibrators with the following concentrations were prepared by serial dilution: $2000,1000,500,250,125,62.5 \mu \mathrm{g} / \mathrm{l}$; a zero-calibrator was used additionally.

\section{Sample preparation and chromatography}

A semi-automated sample preparation with a manual deproteinization step and automated on-line solid-phase extraction employing column-switching was applied.

In $1.5 \mathrm{ml}$ polypropylene cups, $50 \mu \mathrm{l}$ of calibrators or patients' plasma samples were precipitated with $150 \mu \mathrm{l}$ of acetonitrile containing the internal standard at a concentration of $1000 \mu \mathrm{g} / \mathrm{l}$. After vigorous vortex mixing the samples were centrifuged using a non-thermostated standard benchtop centrifuge for $10 \mathrm{~min}$ at $15000 \mathrm{~g} ; 100 \mu \mathrm{l}$ of the clear supernatants were transferred into HPLC vials and placed into the autosampler.

For on-line solid-phase extraction a Waters Oasis HLB ${ }^{\circledR}$ column ( $25 \mu \mathrm{m}, 1.0 \times 50 \mathrm{~mm}$; Waters, Milford, USA) was used together with a Rheodyne six-port high-pressure switching valve (Rheodyne, Rohnert Park, CA, USA) installed into the Waters 2690 separation module and controlled by the Micromass Masslynx 3.4 mass spectrometry software (Micromass, Manchester, UK).

The extraction procedure consisted of three steps: First, $30 \mu \mathrm{l}$ of deproteinized sample was injected and loaded onto the extraction column in valve position A (Figure 2); the mobile phase was water/methanol $95 / 5 \mathrm{v} / \mathrm{v}$ delivered at a flow rate of $3 \mathrm{ml} / \mathrm{min}$; potentially interfering compounds were washed into the waste. In parallel, the analytical column ( $\mathrm{Li}$ Crospher ${ }^{\circledR}$ C18 end-capped $125 \times 4$ mm; $5 \mu \mathrm{m}$, Merck, Darmstadt, Germany) was equilibrated with acetonitrile/2 $\mathrm{mM}$ ammonium acetate $80 / 20 \mathrm{v} / \mathrm{v}$ delivered at a flow rate of $0.85 \mathrm{ml} / \mathrm{min}$. After $1 \mathrm{~min}$ the switching valve changed to position $\mathrm{B}$; the extraction column was now eluted in a back-flush
A

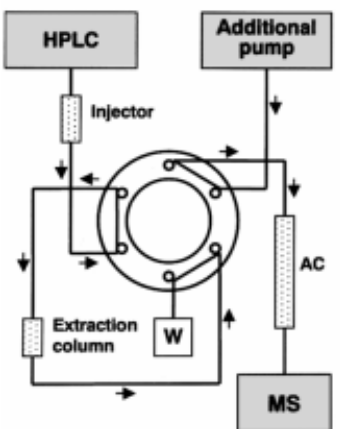

B

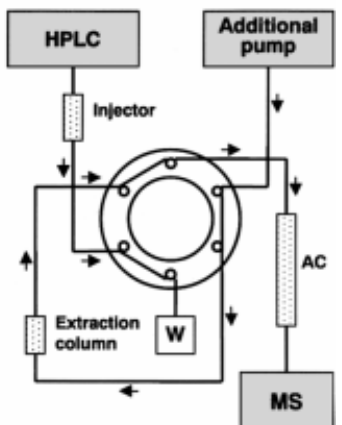

Figure 2 Column switching scheme applied for on-line solidphase extraction of itraconazole, hydroxyitraconazole and the internal standard R51012, respectively. 
mode onto the analytical column. After 2 min the valve switched back to position A. During analytical chromatography into the mass spectrometer in position A, the extraction column was washed with acetonitrile at a flow rate of $3 \mathrm{ml} / \mathrm{min}$ for $1 \mathrm{~min}$ and subsequently was re-equilibrated with water/methanol $95 / 5 \mathrm{v} / \mathrm{v}$. Both extraction and analytical column were kept at $38^{\circ} \mathrm{C}$ in a column oven. The retention times of itraconazole, hydroxyitraconazole and the internal standard were approximately $3.6 \mathrm{~min}, 2.9 \mathrm{~min}$ and $3.9 \mathrm{~min}$, respectively, after injection into the extraction column. The total analytical run time was 5 min.

\section{Mass spectrometric conditions}

Electrospray atmospheric pressure ionization in the positive mode was used; the source parameters were tuned to obtain the following quasi-molecular ions $\left(\left[\mathrm{M}+\mathrm{H}^{+}\right]\right)$of itraconazole, hydroxyitraconazole and the internal standard compound (705 m/z, $721 \mathrm{~m} / \mathrm{z}$, and $733 \mathrm{~m} / \mathrm{z}$, respectively). The following settings resulted in optimal ion yield: capillary voltage, $3.5 \mathrm{kV}$; cone voltage, $55 \mathrm{~V}$; source temperature, $90^{\circ} \mathrm{C}$; desolvation temperature, $250^{\circ} \mathrm{C}$; nitrogen flow, approx. $550 \mathrm{l} / \mathrm{h}$; cone gas flow, approx. $75 \mathrm{l} / \mathrm{h}$. The collision energy with argon as the collision gas was $35 \mathrm{~V}$. Under these conditions several intense product ions were generated for all three analytes. For quantification the following transitions were recorded: itraconazole $705>392$, hydroxyitraconazole $721>408$; internal standard $733>460$. The dwell time for all multiple reaction monitoring (MRM) traces was $0.3 \mathrm{~s}$; interchannel delay and interscan delay were $0.15 \mathrm{~s}$.

\section{Validation}

To study the recovery of the two-step extraction procedure first a solution containing itraconazole, hydroxyitraconazole and the internal standard each at a concentration of $1000 \mu \mathrm{g} / \mathrm{l}$ dissolved in methanol/water (1/1) was introduced directly to the mass spectrometer by loop injection; the peak areas of the respective multiple reaction monitoring traces were recorded. Then a drug-free plasma sample was spiked with the three compounds to obtain the identical final concentration $(1000 \mu \mathrm{g} / \mathrm{l})$; this sample was submitted to the entire analytical method described with the only modification that the flow of the analytical column was reduced to $0.3 \mathrm{ml} / \mathrm{min}$ and no split was applied between HPLC and the mass spectrometer. Again the respective peak areas of the analytes were recorded and recoveries were calculated for the three compounds by comparison with the respective peak areas obtained by direct analysis of the pure solution; the experiment was performed in triplicate.

Linearity of the method was investigated using a spiked plasma sample with a concentration of $10000 \mu \mathrm{g} / \mathrm{l}$ that was diluted stepwise $1+1$ with drug-free plasma to a final concentration of $10 \mu \mathrm{g} / \mathrm{l}$ to perform linear regression analysis. The signal-to-noise ratio of the itraconazole peak and the hydroxyitraconazole peak, respectively, of the sample with the lowest concentration was recorded to estimate the limit of detection of the method.

To study the imprecision of the method, one plasma pool each in a high concentration range and in a low concentration range of itraconazole and hydroxyitraconazole, respectively, was prepared from residual clinical samples, equilibrated overnight, aliquoted and stored at $-80^{\circ} \mathrm{C}$. In three independent series using separately weighted calibration material, each pool was analyzed 4 times to calculate the respective total coefficient of variation.

The presence of ion suppression effects was studied by preparing $1000 \mu \mathrm{g} / \mathrm{l}$ solutions of itraconazole, hydroxyitra- conazole and the internal standard, respectively, in acetonitrile/water (1:1) and separately in drug-free plasma. Both samples were submitted to the entire method but without addition of the internal standard. The respective peak areas of the three analyte-specific multiple reaction monitoring traces were compared between the two samples (acetonitrile/water vs. plasma).

\section{Results}

The parent ion spectrum of itraconazole obtained by electrospray ionization is given in Figure $3 \mathrm{~A}$; an itraconazole molecule containing two $\mathrm{Cl}-35$ atoms (which represent approx. $75 \%$ of naturally occurring chlorine) has a molecular weight of 704 . The mass peak at $705 \mathrm{~m} / \mathrm{z}$ corresponds to the $[\mathrm{M}+\mathrm{H}]+$ ion of this molecule. The intensive isotope peaks found with $\mathrm{m} / \mathrm{z}$ ranging up

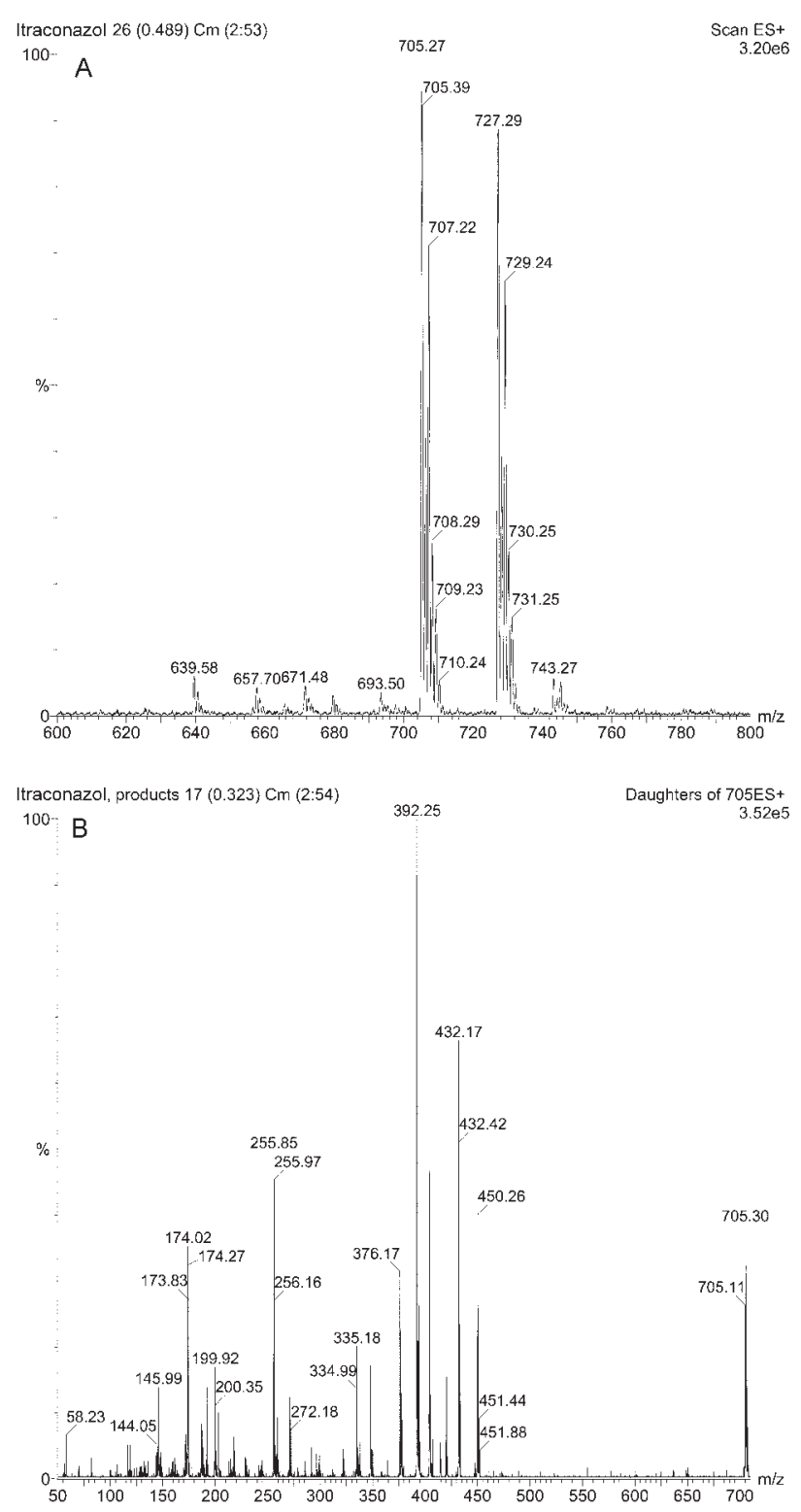

Figure 3 A: Parent ion spectrum of itraconazole obtained by electrospray atmospheric pressure ionization in the positive mode. B: Product ion spectrum of itraconazole generated by collision induced disintegration of a parent ion with $705 \mathrm{~m} / \mathrm{z}$. 
to 710 correspond to itraconazole molecules containing different proportions of $\mathrm{Cl}-37$ atoms. The mass peak at $727 \mathrm{~m} / \mathrm{z}$ represents the sodium adduct of the itraconazole molecule containing two $\mathrm{Cl}-35$ atoms. The collision-induced product ion spectrum obtained from the itraconazole quasi-molecular ion with $705 \mathrm{~m} / \mathrm{z}$ is given in Figure 3B.

A representative chromatogram obtained from a clinical sample is given in Figure 4 (concentration of itraconazole, $115 \mu \mathrm{g} / \mathrm{l}$; concentration of hydroxyitraconazole $127 \mu \mathrm{g} / \mathrm{l}$ ).

Extraction recoveries above $90 \%$ were found for itraconazole, hydroxyitraconazole and the internal standard, respectively (itraconazole, mean recovery $92.3 \%$ (SD 1.2\%); hydroxyitraconazole, mean recovery $94.0 \%$ (SD 1.4\%); internal standard compound, mean recovery $92.7 \%$ (SD $1.7 \%)$ ).

The method proved linear over a range of 10 to $10000 \mu \mathrm{g} / \mathrm{l}$ for both itraconazole and hydroxyitraconazole ( $r>0.999$ for both analytes). In the sample containing $10 \mu \mathrm{g} / \mathrm{l}$ of itraconazole and hydroxyitraconazole, respectively, a signal-to-noise ratio of 37:1 was found for the itraconazole MRM peak and of $42: 1$ for the hydroxyitraconazole peak, respectively.

Total imprecision data for the "low concentration" and the "high concentration" pool are given in Table 1.

Comparison of the peak areas found in a pure solution of itraconazole, hydroxyitraconazole and the internal standard, respectively, in methanol/water (1:1) and

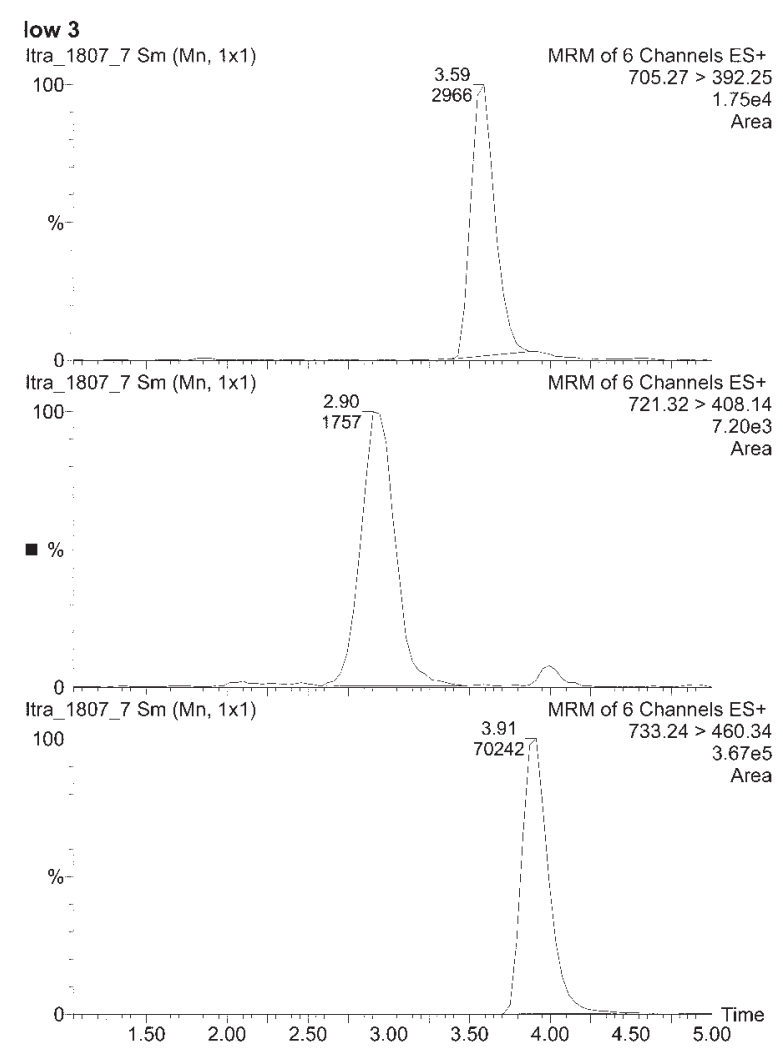

Figure 4 Representative chromatograms of itraconazole, hydroxyitraconazole and the internal standard R51012 obtained from a clinical sample (itraconazole, $115 \mu \mathrm{g} / \mathrm{l}$; hydroxyitraconazole, $127 \mu \mathrm{g} / \mathrm{l})$.
Table 1 Total imprecision data for the quantification of itraconazole and hydroxyitraconazole using liquid chromatography-tandem mass spectrometry for a low- and a high-analyte concentration pool $(n=12)$.

\begin{tabular}{lll}
\hline & $\begin{array}{l}\text { Low- } \\
\text { concentration } \\
\text { pool }\end{array}$ & $\begin{array}{l}\text { High- } \\
\text { concentration } \\
\text { pool }\end{array}$ \\
\hline $\begin{array}{lll}\text { Itraconazole, mean } & 115 \mu \mathrm{g} / \mathrm{l} & 994 \mu \mathrm{g} / \mathrm{l} \\
\text { coefficient of variation } & 5.1 \% & 4.8 \% \\
\text { Hydroxyitraconazole, mean } \\
\text { coefficient of variation }\end{array}$ & $\begin{array}{l}127 \mu \mathrm{g} / \mathrm{l} \\
5.2 \%\end{array}$ & $\begin{array}{l}1150 \mu \mathrm{g} / \mathrm{l} \\
4.9 \%\end{array}$ \\
\hline
\end{tabular}

found in a plasma sample with the same concentration of the respective analytes (each $1000 \mu \mathrm{g} / \mathrm{l}$ ) did not show relevant differences, ruling out ion-suppression effects.

\section{Discussion}

In this manuscript, for the first time, a rugged and convenient method for the simultaneous quantification of the anti-mycotic drug itraconazole and its co-active metabolite hydroxyitraconazole employing LC-TMS is described.

Validation data demonstrate the applicability of the method to clinical analyses. The availability of stable isotope-labeled itraconazole as the internal standard compound would probably further increase the precision of the method that at present involves a dimethyl homolog of itraconazole as the internal standard compound.

Since a preliminary itraconazole target plasma concentration for neutropenic patients at risk of systemic fungal infections has been established (>500 $\mu \mathrm{g} / \mathrm{l})$, measurement of itraconazole is gaining particular importance for the clinical laboratory. HPLC methods have been in use for the determination of itraconazole in plasma for more than 10 years, applying different techniques of extraction (solvent extraction, solidphase extraction or mere protein precipitation), as well as different techniques of detection (UV, fluorescence, diode array detection) (18-27, 29, 31). These methods, however, have important drawbacks with respect to their specificity. In our experience with conventional HPLC methods for simultaneous quantification of itraconazole and hydroxyitraconazole in a large proportion of individual "drug-free" human plasma samples, interference arises from undefined compounds that coelute with the target analytes. Such interference from endogenous compounds is found in individual samples even if analytical run times above 20 min and gradient elution programs are applied.

Specificity of conventional HPLC methods can in principle be tested with respect to commonly used parent drug compounds; particularly in severely ill patients treated with large numbers of different drugs and often 
impaired renal or hepatic function. However, co-elution of drug metabolites together with itraconazole or hydroxyitraconazole (leading to falsely high results) or with the internal standard compound (leading to falsely low results) must principally be taken into consideration when unspecific detection techniques such as UV detection are applied. It is as well a potential limitation of unspecific techniques of HPLC detection that co-elution of itraconazole, hydroxyitraconazole or the internal standard compound, together with one of the many further metabolites of itraconazole, may occur. Itraconazole is described to be subject to extensive hepatic metabolization; however, very little data is available on this issue $(10,11)$. A fully reliable validation of HPLC methods using conventional techniques of detection would require all metabolites as pure substances for specificity investigations. These metabolites, however, are not generally available. Due to the high specificity of the LC-TMS technology applied in the method described here, in contrast to UV or fluorescence detection, analytical interference from drugs or drug metabolites is very unlikely. In LC-TMS - after soft ionization of the compounds having eluted from the HPLC - the parent ion of a respective target compound is filtered according to its mass-to-charge ratio in a first mass spectrometer; this parent ion is submitted to disintegration by collision with argon, generating an analyte-specific spectrum of product ions. One selected characteristic ion of these product ions is again filtered according to its mass-to-charge ratio in a second mass spectrometer to finally reach the ion detector. Using two mass spectrometers in line with an interposed collision cell, potential interference from other drugs, metabolites or endogenous compounds, as well as unspecific background "noise", is minimized in TMS allowing highly specific and sensitive analyses.

Due to these technical characteristics, LC-TMS in general requires very limited sample preparation. In our experience, however, mere protein precipitation as applied in several previously reported conventional HPLC methods for itraconazole quantification results in a short lifetime of the HPLC columns and the electrospray capillaries. Moreover, in LC-TMS residual matrix constituents may interfere with electrospray ionization of target compounds. Sample preparation by solvent extraction or manual off-line solid-phase extraction is time-consuming and would critically limit the sample throughput. On-line solid-phase extraction after protein precipitation - as applied in the method described here - increases the analytical run time by only $1 \mathrm{~min}$ per sample compared to mere protein precipitation and does not require additional manual handling steps but this approach results in very stable chromatographic results, efficient ionization and minimal spoiling of the electrospray capillary and ion source parts. In order to further minimize potential ion suppression effects after automated sample preparation and to further increase specificity (32), a certain degree of chromatographic separation has proven to be useful in TMS assays with overall run times of about $5 \mathrm{~min}$ as in the present method.
Given the typically high plasma concentration ranges of itraconazole and hydroxyitraconazole, analytical methods employing single stage liquid chromatography-mass spectrometry (LC-MS) systems - which do not apply the principle of collision-induced generation of product ions - have been shown to be applicable to biological samples $(28,30)$. Compared to singlestage LC-MS, however, LC-TMS is likely to experience far more widespread use in clinical laboratories, because specificity and sensitivity of this latter technology is by far superior, with the instruments' costs being higher by about $30 \%$. Therefore, the convenient LC-TMS method reported here is of practical interest for a continuously growing number of laboratories equipped with LC-TMS systems and offers substantial improvement in the monitoring of itraconazole and hydroxyitraconazole.

\section{Acknowledgements}

The standard compounds used in our investigation were a kind gift from ORTHO BIOTECH, a division of Janssen-Cilag, Neuss, Germany.

\section{References}

1. Vogeser M, Wanders A, Haas A, Ruckdeschel G. A four-year review of fatal Aspergillosis. Eur J Clin Microbiol Infect Dis $1999 ; 18: 42-5$.

2. Lin SJ, Schranz J, Teutsch SM. Aspergillosis case-fatality rate: systematic review of the literature. Clin Infect $D$ is 2001; 32:358-66.

3. Hughes WT, Armstrong D, Bodey GP, Bow EJ, Brown AE, Calandra T, et al. 2002 guidelines for the use of antimicrobial agents in neutropenic patients with cancer. Clin Infect Dis 2002; 34:730-51.

4. Menichetti F, Del Favero A, Martino P, Bucaneve G, Micozzi A, Girmenia C, et al. Itraconazole oral solution as prophylaxis for fungal infections in neutropenic patients with hematologic malignancies: a randomized, placebo-controlled, double-blind, multicenter trial. GIMEMA Infection Program. Gruppo Italiano Malattie Ematologiche dell' Adulto. Clin Infect Dis 1999; 28:250-5.

5. Boogaerts M, Maertens J, van Hoof A, de Bock R, Fillet G, Peetermans $M$, et al. Itraconazole versus amphotericin $B$ plus nystatin in the prophylaxis of fungal infections in neutropenic cancer patients. J Antimicrob Chemother 2001; 48:97-103.

6. Boogaerts M, Winston DJ, Bow EJ, Garber G, Reboli AC, Schwarer AP, et al. Intravenous and oral itraconazole versus intravenous amphotericin B deoxycholate as empirical antifungal therapy for persistent fever in neutropenic patients with cancer who are receiving broad-spectrum antibacterial therapy. A randomized, controlled trial. Ann Intern Med 2001; 135:412-22.

7. Caillot D, Bassaris H, McGeer A, Arthur C, Prentice HG, Seifert $\mathrm{W}$, et al. Intravenous itraconazole followed by oral itraconazole in the treatment of invasive pulmonary aspergillosis in patients with hematologic malignancies, chronic granulomatous disease, or AIDS. Clin Infect Dis 2001; 33:e83-90.

8. Vandewoude K, Vogelaers D, Decruyenaere J, Jaqmin P, De Beule K, Van Peer A, et al. Concentrations in plasma and 
safety of 7 days of intravenous itraconazole followed by 2 weeks of oral itraconazole solution in patients in intensive care units. Antimicrob Agents Chemother 1997; 41:27148.

9. Boogaerts MA, Maertens J, Van Der Geest R, Bosly A, Michaux JM, Van Hoof $A$, et al. Pharmacokinetics and safety of a 7-day administration of intravenous itraconazole followed by a 14-day administration of itraconazole oral solution in patients with hematologic malignancy. Antimicrob Agents Chemother 2001; 45:981--5.

10. Heykants J, Van Peer A, Van de Velde V, Van Rooy P, Meuldermans W, Lavrijsen $\mathrm{K}$, et al. The clinical pharmacokinetics of itraconazole: an overview. Mycoses 1989; 32 Suppl 1:67-87.

11. Grant SM, Clissold SP. Itraconazole. A review of its pharmacodynamic and pharmacokinetic properties, and therapeutic use in superficial and systemic mycoses. Drugs $1989 ; 37: 310-44$.

12. Odds FC, Bossche HV. Antifungal activity of itraconazole compared with hydroxy-itraconazole in vitro. J Antimicrob Chemother 2000; 45:371-3.

13. Adriaenssens B, Roskams T, Steger P, Van Steenbergen W. Hepatotoxicity related to itraconazole: report of three cases. Acta Clin Belgica 2001; 56:364-9.

14. Rex JH, Pfaller MA, Galgiani JN, Bartlett MS, Espinel-Ingroff A, Ghannoum MA, et al. Development of interpretive breakpoints for antifungal susceptibility testing: conceptual framework and analysis of in vitro-in vivo correlation data for fluconazole, itraconazole, and candida infections. Subcommittee on Antifungal Susceptibility Testing of the National Committee for Clinical Laboratory Standards. Clin Infect Dis 1997; 24:235-47.

15. Poirier JM, Cheymol G. Optimisation of itraconazole therapy using target drug concentrations. Clin Pharmacokinet 1998; 35:461-73.

16. Glasmacher A, Hahn C, Leutner C, Molitor E, Wardelmann $\mathrm{E}$, Losem $\mathrm{C}$, et al. Breakthrough invasive fungal infections in neutropenic patients after prophylaxis with itraconazole. Mycoses 1999; 42:443-51.

17. Boogaerts M, Maertens J. Clinical experience with itraconazole in systemic fungal infections. Drugs 2001; 61 Suppl 1:39-47.

18. Woestenborghs R, Lorreyne W, Heykants J. Determination of itraconazole in plasma and animal tissues by high-performance liquid chromatography. J Chromatogr 1987; 413:332-7.

19. Allenmark S, Edebo A, Lindgren K. Determination of itraconazole in serum with high-performance liquid chromatography and fluorescence detection. J Chromatogr 1990; 532:203-6.

20. Badcock NR. Micro-scale method for itraconazole in plasma by reversed-phase high-performance liquid chromatography. J Chromatogr 1990; 525:478-83.

21. Poirier JM, Lebot M, Descamps P, Levy M, Cheymol G. Determination of itraconazole and its active metabolite in plasma by column liquid chromatography. Ther Drug Monit 1994; 16:596-601.
22. Darouiche RO, Setoodeh A, Anaissie EJ. Potential use of a simplified method for determination of itraconazole levels in plasma and esophageal tissue by using high-performance liquid chromatography. Antimicrob Agents Chemother 1995; 39:757-9.

23. Lacroix C, Wojciechowski F, Danger P. Simultaneous determination of itraconazole, hydroxy-itraconazole and amphotericin B in human plasma by HPLC with photodiode array detection. Ann Biol Clin 1995; 53:293-7.

24. Rifai N, Sakamoto M, Platt O, Brugnara C. A high-performance liquid chromatographic assay for the determination of itraconazole concentration using solid-phase extraction and small sample volume. Ther Drug Monit 1995; 17:522-5.

25. Compas D, Touw DJ, de Goede PN. Rapid method for the analysis of itraconazole and hydroxyitraconazole in serum by high-performance liquid chromatography. J Chromatogr B Biomed Appl 1996; 687:453-6.

26. Ng TK, Chan RC, Adeyemi-Doro FA, Cheung SW, Cheng AF. Rapid high performance liquid chromatographic assay for antifungal agents in human sera. J Antimicrob Chemother 1996; 37:465-72.

27. Gubbins PO, Gurley BJ, Bowman J. Rapid and sensitive high performance liquid chromatographic method for the determination of itraconazole and its hydroxy-metabolite in human serum. J Pharm Biomed Anal 1998; 16:1005-12.

28. Carrier A, Parent J. Liquid chromatographic-mass spectrometric determination of itraconazole and its major metabolite, hydroxyitraconazole, in dog plasma. J Chromatogr B Biomed Sci Appl 2000; 745:413-20.

29. Al-Rawithi S, Hussein R, Al-Moshen I, Raines D. Expedient microdetermination of itraconazole and hydroxyitraconazole in plasma by high-performance liquid chromatography with fluorescence detection. Ther Drug Monit 2001; 23:445-8.

30. Yao M, Chen L, Srinivas NR. Quantitation of itraconazole in rat heparinized plasma by liquid chromatography-mass spectrometry. J Chromatogr B Biomed Sci Appl 2001; 752:9-16.

31. Koks CH, Sparidans RW, Lucassen G, Crommentuyn KM, Beijnen JH. Selective high-performance liquid chromatographic assay for itraconazole and hydroxyitraconazole in plasma from human immunodeficiency virus-infected patients. J Chromatogr B Biomed Sci Appl 2002; 767:103-10.

32. Vogeser M, Zachoval R, Spöhrer U, Jacob K. Potential lack of specificity using electrospray tandem-mass spectrometry for the analysis of mycophenolic acid in serum. Therapeutic Drug Monit 2001; 23:722-4.

Received 23 January 2003, revised 30 April 2003, accepted 9 May 2003

Corresponding author: Dr. med. Michael Vogeser, Institut für Klinische Chemie, Klinikum der Universität München-

Großhadern, 81366 Munich, Germany

Phone: 004989 / 7095 3246, Fax: 004989 / 7095 3240,

E-mail: Michael.Vogeser@klch.med.uni-muenchen.de 